OPEN ACCESS

Edited by:

Faith H. A. Osier,

KEMRI Wellcome Trust Research

Programme, Kenya

Reviewed by:

Werner Solbach,

Universität zu Lübeck, Germany

Mark W. Robinson,

Queen's University Belfast,

United Kingdom

*Correspondence:

Hany M. Elsheikha

hany.elsheikha@nottingham.ac.uk

Xing-Quan Zhu

xingquanzhu1@hotmail.com

Specialty section:

This article was submitted to

Microbial Immunology,

a section of the journal

Frontiers in Immunology

Received: 07 April 2019 Accepted: 08 July 2019 Published: 23 July 2019

Citation:

Chen D, Tian A-L, Hou J-L, Li J-X, Tian X, Yuan X-D, Li X, Elsheikha HM and Zhu X-Q (2019) The Multitasking

Fasciola gigantica Cathepsin $B$ Interferes With Various Functions of Goat Peripheral Blood Mononuclear

Cells in vitro.

Front. Immunol. 10:1707. doi: 10.3389/fimmu.2019.01707

\section{The Multitasking Fasciola gigantica Cathepsin B Interferes With Various Functions of Goat Peripheral Blood Mononuclear Cells in vitro}

\author{
Dan Chen ${ }^{1,2}$, Ai-Ling Tian ${ }^{1}$, Jun-Ling Hou ${ }^{1}$, Jie-Xi Li ${ }^{1}$, XiaoWei Tian ${ }^{3}$, Xiao-Dan Yuan ${ }^{1}$, \\ Xiangrui Li ${ }^{3}$, Hany M. Elsheikha ${ }^{4 *}$ and Xing-Quan Zhu ${ }^{1 *}$

\begin{abstract}
${ }^{1}$ State Key Laboratory of Veterinary Etiological Biology, Key Laboratory of Veterinary Parasitology of Gansu Province, Lanzhou Veterinary Research Institute, Chinese Academy of Agricultural Sciences, Lanzhou, China, ${ }^{2}$ College of Veterinary Medicine, Northwest A\&F University, Yangling, China, ${ }^{3}$ College of Veterinary Medicine, Nanjing Agricultural University, Nanjing, China, ${ }^{4}$ Faculty of Medicine and Health Sciences, School of Veterinary Medicine and Science, University of Nottingham, Loughborough, United Kingdom
\end{abstract}

Cathepsin B, a lysosomal cysteine protease, is thought to be involved in the pathogenesis of Fasciola gigantica infection, but its exact role remains unclear. In the present study, a recombinant F. gigantica cathepsin B (rFgCatB) protein was expressed in the methylotrophic yeast Pichia pastoris. Western blot analysis confirmed the reactivity of the purified $r F g C a t B$ protein to serum from $F$. gigantica-infected goats. The effects of serial concentrations $(10,20,40,80$, and $160 \mu \mathrm{g} / \mathrm{ml})$ of $r F g C a t B$ on various functions of goat peripheral blood mononuclear cells (PBMCs) were examined. We demonstrated that $r F g C a t B$ protein can specifically bind to the surface of PBMCs. In addition, $r F g C a t B$ increased the expression of cytokines (IL-2, IL-4, IL-10, IL-17, TGF- $\beta$, and IFN- $\gamma$ ), and increased nitric oxide production and cell apoptosis, but reduced cell viability. These data show that $r F g C a t B$ can influence cellular and immunological functions of goat PBMCs. Further characterization of the posttranslational modification and assessment of rFgCatB in immunogenicity studies is warranted.

Keywords: Fasciola gigantica, cysteine protease, cathepsin B, immunomodulation, host-parasite interaction

\section{INTRODUCTION}

Fasciolosis, caused by the liver flukes Fasciola gigantica (F. gigantica) and Fasciola hepatica (F. hepatica), is an important parasitic disease with a worldwide distribution (1). These liver flukes can infect a wide range of mammalian species, including livestock, wild animals, and humans. F. gigantica is responsible for significant economic losses in the buffalo-producing countries due to its chronic morbidity and adverse effects on the animal health, fecundity, and productivity (2). Adding to the challenge is the emerging evidence of F. gigantica resistance against albendazole and rafoxanide (3), and the lack of a commercial vaccine. Better understanding of the mechanisms and factors that shape the immuno-pathogenesis of fasciolosis may ultimately facilitate the design of new immunotherapeutic strategies for efficient treatment of fasciolosis.

Fasciola spp. employ multiple strategies to evade the host immune response using various molecules in their excretory/secretory (E/S) products (4-7), such as cathepsin B and L proteases $(8-10)$. At least six types of cathepsin B have been detected in the immature and invasive stages 
of Fasciola, and have been shown to play roles in the pathogenesis of fasciolosis $(9,11,12)$. Due to their immune-modulatory functions, cysteine proteases such as cathepsin B have attracted significant attention as potential immuno-therapeutic targets to control liver fluke infection (9).

In $F$. hepatica, cathepsins interact with host immune cells and skew the immune response toward a non-protective Th2mediated/regulatory response (13). In F. gigantica, cathepsin B2 and B3 digest host substrates, such as immunoglobulin, fibronectin, and collagen (14-16). Also, cathepsin B5, expressed in immature and adult stages of $F$. gigantica, can digest host proteins (17). The recombinant proteins (rFgCatB2 and rFgCatB3) can elicit a mixed Th1/Th2 immune response with the predominance of Th2 cytokines (16). Despite significant efforts, information about the modulatory effects of $F$. gigantica cathepsin B on the host innate immune cells is still limited.

In the present study, the gene encoding $F$. gigantica cathepsin B was cloned and expressed in Pichia pastoris. We characterized the modulatory effects of the purified recombinant F. gigantica cathepsin B protein ( $\mathrm{rFgCatB})$ on various functions of goat peripheral blood mononuclear cells (PBMCs), including cytokine secretion, cell viability, nitric oxide (NO) production, and apoptosis. We show that $\mathrm{rFgCatB}$ induces a mixed Th1/Th2/Th17 immune response and significantly influences other functions of goat PBMCs. Our findings demonstrate the feasibility of including $\mathrm{rFgCatB}$ protein in a vaccination trial against fasciolosis.

\section{MATERIALS AND METHODS}

\section{Ethics Statement}

All experimental protocols were reviewed and approved by the Animal Administration and Ethics Committee of Lanzhou Veterinary Research Institute, Chinese Academy of Agricultural Sciences (Permit No. 2018-012). All animal experiments were performed in strict compliance with the Animal Ethics Procedures and Guidelines of the People's Republic of China. All efforts were made to minimize the suffering of animals, and daily health checks were performed during the entire experiments.

\section{Animals and Collection of Blood Cells}

Eight local crossbred goats (4- to 7-month-old) were obtained from Laboratory Animal Center of Lanzhou Veterinary Research Institute, Chinese Academy of Agriculture Science. All goats were kept in-door and dewormed with albendazole and ivermectin tablets (Xining Fengyuan Agricultural and Animal Sci-Tech Company, Xining, China) to eliminate any potential existing helminth infection. Before and 2 weeks after treatment, fecal samples from each goat were microscopically examined for helminth eggs. This analysis showed that all goats used in the study are free from any prior or current helminth infection. For the production of antisera, four female New Zealand rabbits (3-month-old) were purchased from Laboratory Animal Center of Lanzhou Veterinary Research Institute, Chinese Academy of Agriculture Science and were housed under specificpathogen-free conditions, with access to food and water ad libitum. Peripheral venous blood samples were collected from three healthy goats and peripheral blood mononuclear cells (PBMCs) and monocytes were isolated and cultured as previously described (7).

\section{Parasite Preparation}

Adult flukes were harvested from the gall bladder of naturally infected buffaloes at local slaughterhouses in Guangxi Zhuang Autonomous Region, PR China. The harvested flukes were washed with phosphate buffered saline (PBS, pH7.4) and immediately used for RNA isolation or stored at $-80^{\circ} \mathrm{C}$ with RNA stabilizer for future use. The flukes were identified as $F$. gigantica based on amplification and sequencing of the internal transcribed spacer 2 (ITS-2) of the ribosomal DNA (18). Sequence alignment showed no difference between the ITS-2 sequence obtained in our study and the ITS2 sequence obtained previously from $F$. gigantica samples collected from buffaloes in Guangxi province (GenBank accession No. AJ557569).

\section{Cloning and Characterization of FgCatB Gene}

Due to the lack of genomics data on $F$. gigantica, we have searched $F$. hepatica E/S product's dataset produced by liquid chromatography-tandem mass spectrometry (LCMS/MS), F. hepatica cDNA library available from previous proteomic studies, and the BLASTx search protein database (https://blast.ncbi.nlm.nih.gov/Blast.cgi), in order to identify homologous cathepsin B protein sequences. This analysis identified F. hepatica cathepsin B protein isoform (FhCatB) sequence (GenBank accession No. Z22768.1), which was used to design primers to amplify F. gigantica cathepsin B (FgCatB) gene sequence. Total $F$. gigantica RNA was isolated from $30 \mathrm{mg}$ of adult F. gigantica flukes using Trizol reagent (Invitrogen, San Diego, USA). The first-strand cDNA was synthesized by reverse transcription polymerase chain reaction (RT-PCR) using RevertAid First Strand cDNA Synthesis Kit (Thermo Scientific, (EU) Lithuania). The cDNA was used as a template to amplify $\mathrm{FgCatB}$ gene using two oligonucleotide primers: $5^{\prime}$ CCG GAA TTC CAT ATG AGC TTA CTG ATC TCC AGC$3^{\prime}$ (forward) and 5'- ATT TGC GGC CGC CTC GAG TTG GGG TAA TTT TGG C-3' (reverse). The oligonucleotide primers were synthesized with the EcoRI (forward) or Not I (reverse) restriction site underlined. The resulting amplified $\mathrm{FgCatB}$ gene product was digested with EcoR I and Not I, and cloned into pMD19-T (Takara, Dalian, Liaoning, China). The recombinant plasmid was transformed into Trans $5 \alpha$ chemically competent cells (TransGen Biotech, Beijing, China). Several positive clones were selected and sequenced by GenScript (Nanjing, Jiangsu, China) to confirm the correct insertion/orientation of FgCatB gene in the vector. The signal peptide, transmembrane helices (TMHs) and $\mathrm{N}$-glycosylation sites of the $\mathrm{FgCatB}$ sequence were predicted using SignalP 5.0 Server (http://www.cbs.dtu.dk/ services/SignalP/), TMHMM Server v. 2.0 (http://www.cbs.dtu. $\mathrm{dk} /$ services/TMHMM/), and NetNGlyc 1.0 Server (http://www. cbs.dtu.dk/services/NetNGlyc/), respectively. 


\section{Expression of rFgCatB Protein}

A single positive clone containing the $\mathrm{FgCatB}$ gene was selected and the $\mathrm{FgCatB}$ gene fragment was sub-cloned into pPIC9K vector. A carboxyl-terminal His6 tag and appropriate restriction sites were included in the expression plasmid to enable purification. The plasmid designated as pPIC9K-FgCatB was linearized with $\mathrm{Sal}$ I and electroporated into the methylotrophic yeast $P$. pastoris GS115 strain using a GenePulser X cell TM (BioRad, Hercules, California, USA). Positive recombinant $P$. pastoris clones containing the insert were selected for expression by inoculating into $15 \mathrm{ml}$ of buffered complex medium containing glycerol (BMGY). The inoculated BMGY medium (1\% [wt/vol] yeast extract, $2 \%$ [wt/vol] peptone, $1 \%[\mathrm{wt} / \mathrm{vol}]$ yeast nitrogen base, $1 \%$ [wt/vol] glycerol, $0.00004 \%$ [wt/vol] biotin, and $0.1 \mathrm{M}$ potassium phosphate $[\mathrm{pH} 6.0]$ ) in $100 \mathrm{ml}$ conical flasks was incubated at $28^{\circ} \mathrm{C}$ with vigorous shaking for $24 \mathrm{~h}$. The cells were harvested by centrifugation $(250 \times \mathrm{g}$ for $10 \mathrm{~min})$, resuspended in $20 \mathrm{ml}$ of buffered complex medium containing methanol (BMMY; BMGY medium with $1 \%$ methanol substituted for glycerol). The culture was allowed to continue growing for 4 days. During $\mathrm{FgCatB}$ gene expression induction period, methanol was added every $24 \mathrm{~h}$ to maintain a final concentration of $1 \%$ $(\mathrm{v} / \mathrm{v})$. The cells were pelleted by centrifugation $(2,500 \times \mathrm{g}$ at $4^{\circ} \mathrm{C}$ for $10 \mathrm{~min}$ ) and the culture supernatant was harvested for protein extraction.

\section{Purification of Recombinant $F$. gigantica Cathepsin B ( $\mathrm{Fg}$ CatB) Protein}

The yeast culture supernatant containing rFgCatB protein was concentrated by centrifugation at $4,000 \times \mathrm{g}$ for $15 \mathrm{~min}$ using Amicon ${ }^{\circledR}$ Ultra $10 \mathrm{~K}$ centrifugal filter device. The concentrated supernatant was purified using the His GaviTrap Kit (GE Healthcare, Buckinghamshire, UK) at $4^{\circ} \mathrm{C}$. The rFgCatB protein was eluted with elution buffer (20 mM PBS, $0.5 \mathrm{M} \mathrm{NaCl}, 500 \mathrm{mM}$ imidazole, $\mathrm{PH} 7.4$ ) and dialyzed against $1 \times \mathrm{PBS}$ to remove imidazole. The concentration of the protein was determined by the Bradford method, using bovine serum albumin (BSA) as the standard. Purified proteins were stored at $-80^{\circ} \mathrm{C}$ until further analysis.

\section{Preparation of Antibodies}

Four, 4- to 7-month-old, goats were challenged orally with 250 viable encysted metacercariae of $F$. gigantica. After 3 months, the goat sera containing anti- $F$. gigantica antibodies were collected. Serum was collected from one healthy naïve goat (negative control) and stored frozen at $-80^{\circ} \mathrm{C}$. Specific antibodies against rFgCatB protein were produced by immunizing three New Zealand rabbits with $\mathrm{rFgCatB}$. For primary immunization, 200 $\mu \mathrm{g}$ of the purified $\mathrm{rFgCatB}$ protein mixed with complete Freund's adjuvant (1:1) were injected subcutaneously into multiple sites at the back of the rabbits, followed by four booster doses with 100 $\mu \mathrm{g}$ of the recombinant protein in incomplete Freund's adjuvant at 2-week intervals. One week after the last injection, antisera against $\mathrm{rFgCatB}$ was collected. In the meantime, serum was collected from one healthy rabbit (negative control) and stored frozen at $-80^{\circ} \mathrm{C}$.

\section{SDS-PAGE and Western Blotting}

The isolated protein $(20 \mu \mathrm{g})$ was separated on $12 \%$ sodium dodecyl sulfate (SDS)-polyacrylamide gel electrophoresis (PAGE) gels and stained with Coomassie Blue. The protein migrated on gels as a "blurred" smear without showing the expected band size, indicating that $\mathrm{rFgCatB}$ is a glycoslyated protein. Therefore, rFgCatB was deglycosylated under denaturing conditions using Protein Deglycosylation Mix II (New England Biolab ${ }^{\circledR}$ Inc., USA), as per the manufacturer's instructions. The deglycosylated rFgCatB protein was resolved on $12 \%$ SDS-PAGE gels, followed by Coomassie Blue staining. Also, the deglycosylated rFgCatB was transferred onto Hybond-C extra nitrocellulose membrane (Amersham, London, UK). The membrane was blocked using 5\% skim milk in Tris-buffered saline containing 0.1\% Tween-20 (TBST) for $2 \mathrm{~h}$ at ambient temperature, followed by incubation with primary antibodies (antiserum from goats experimentally infected with $F$. gigantica) for $12 \mathrm{~h}$ at $4^{\circ} \mathrm{C}(1: 100$ in TBST). After being washed three times ( 5 min each) with TBST, the membrane was incubated with HRP-conjugated rabbit anti-goat IgG (Sigma, St. Louis, MO, USA) for $1 \mathrm{~h}$ at $37^{\circ} \mathrm{C}(1: 2500$ in TBST). Finally, freshly prepared $3,3^{\prime}$-diaminobenzidine (DAB, Sigma) was used as a chromogenic substrate to visualize the immunoreaction.

\section{Measurement of rFgCatB Activity}

The enzyme activity of $\mathrm{rFgCatB}$ was measured using Cathepsin B Activity Assay Kit (Abcam, ab65300) according to the manufacturer's instructions. Briefly, $50 \mu \mathrm{g}$ of $\mathrm{rFgCatB}$ protein was adjusted to $50 \mu \mathrm{L}$ per well with cell lysis buffer for experimental samples in a 96-well plate. Fifty microliters of blank cell lysis buffer were used for measuring background. Next, $50 \mu \mathrm{L}$ CB Reaction Buffer followed by $2 \mu \mathrm{L}$ of cathepsin B substrate Ac-RR-AFC (amino-4-trifluoromethyl coumarin) were added to each well. The plates were incubated at $37^{\circ} \mathrm{C}$ for $2 \mathrm{~h}$ protected from light, and fluorescence from the cathepsin B-cleaved substrate was measured at excitation/emission $(\mathrm{Ex} / \mathrm{Em})=400 / 505 \mathrm{~nm}$ using a fluorescent microplate reader (Thermo scientific, Varioskan LUX Multimode Microplate Reader). The relative enzyme activity of $\mathrm{rFgCatB}$ was represented as the fold increase in the fluorescence intensity compared with the cathepsin B inhibitor-treated control.

\section{Immunofluorescence Detection of rFgCatB Protein Binding to Goat PBMCs}

Goat PBMCs were incubated with $10 \mu \mathrm{g} / \mathrm{ml}$ of $\mathrm{rFgCatB}$ in a humidified atmosphere of $5 \% \mathrm{CO}_{2}$ at $37^{\circ} \mathrm{C}$ for $1 \mathrm{~h}$. The $\mathrm{rFgCatB}-$ treated cells were fixed with $4 \%$ paraformaldehyde at ambient temperature for $15 \mathrm{~min}$, washed three times in PBS ( 5 min each), and subsequently treated with blocking solution (4\% BSA in PBS) for $1 \mathrm{~h}$ to minimize background staining. rFgCatB-treated or non-treated control PBMCs were incubated with rabbit antirFgCatB antibody (dilution, $1: 100$ ) for $12 \mathrm{~h}$ at $4^{\circ} \mathrm{C}$ and washed three times in PBS ( 5 min each). Cells were stained with Cy3 conjugated goat anti-rabbit IgG secondary antibody (dilution, 1:500) (Beyotime, Haimen, Jiangsu, China) for $1 \mathrm{~h}$ at $37^{\circ} \mathrm{C}$. Hoechst 33342 (Invitrogen, Eugene, Oregon, USA) was used to stain the nucleus. Localization of $\mathrm{rFgCatB}$ was visualized using a Zeiss laser scanning confocal microscope (LSM710, Zeiss, Jena, 
Germany) at $100 \times$ magnification and images were analyzed using Zen 2012 imaging software.

\section{Cytokine Analysis}

The concentrations of cytokines were evaluated in the supernatant of $5 \times 10^{4} \mathrm{PBMCs}$ seeded into 24-well tissue culture plates in $1 \mathrm{ml}$ RPMI 1640 medium/well. Serial concentrations (10, $20,40,80$, and $160 \mu \mathrm{g} / \mathrm{ml}$ ) of $\mathrm{rFgCatB}$ protein or equal volume of PBS (control) were added to the wells. The culture plates were incubated at $37^{\circ} \mathrm{C}$ with $5 \% \mathrm{CO}_{2}$ for $72 \mathrm{~h}$. The supernatants were collected and the concentrations of interleukin-2 (IL-2), IL-4, IL-10, IL-17, interferon gamma (IFN- $\gamma$ ), and transforming growth factor-beta (TGF- $\beta$ ) were determined using goat enzyme linked immunosorbent assay (ELISA) kits (Mlbio, Shanghai, China) as per the manufacturer's instructions.

\section{The Effect of rFgCatB Protein on Cell Viability}

The effect of $\mathrm{rFgCatB}$ protein on the viability of PBMCs was examined by a CCK- 8 assay (Beyotime, Haimen, Jiangsu, China). This assay is based on the measurement of the reduction of a water-soluble tetrazolium salt WST- 8 by dehydrogenases in viable cells. Briefly, PBMCs $\left(10^{4}\right.$ cells/100 $\mu \mathrm{l}$ RPMI 1640 medium/well) seeded into 96-well tissue culture plates were incubated with serial concentrations $(10,20,40,80$, or $160 \mu \mathrm{g} / \mathrm{ml}$ ) of rFgCatB protein or equal volume of PBS (control) at $37^{\circ} \mathrm{C}$ in a humidified atmosphere with $5 \% \mathrm{CO}_{2}$. Following $48 \mathrm{~h}$ incubation, $10 \mu \mathrm{l}$ of CCK- 8 reagent were added per well and the culture plates were further incubated under the same conditions for $4 \mathrm{~h}$ in protected from light. The optical density at $450 \mathrm{~nm}\left(\mathrm{OD}_{450}\right)$ was measured using a microplate reader (BioRad, Hercules, California, USA). The $\mathrm{OD}_{450}$ of control wells (cells incubated with PBS) was set as $100 \%$ and the cell viability index was calculated using the formula: $\mathrm{OD}_{450} \mathrm{rFgCatB} / \mathrm{OD}_{450}$ control.

\section{Determination of Nitric Oxide (NO)}

PBMCs were seeded into a 24 -well tissue culture plate at $5 \times$ $10^{4}$ cells/well in $1 \mathrm{ml}$ RPMI 1640 medium. Cells were incubated with various concentrations $(10,20,40$, or $80 \mu \mathrm{g} / \mathrm{ml})$ of $\mathrm{rFgCatB}$ protein or equal volume of PBS (control) at $37^{\circ} \mathrm{C}$ with $5 \%$ $\mathrm{CO}_{2}$ for $24 \mathrm{~h}$. The NO level in PBMC culture supernatant was determined by measuring the concentrations of nitrite using the Total Nitric Oxide Assay Kit (Beyotime, Haimen, Jiangsu, China). A microplate reader (Bio-Rad, Hercules, California, USA) was used to measure the absorbance values at $540 \mathrm{~nm}$ $\left(\mathrm{OD}_{540}\right)$. NO levels were calculated using a standard curve generated by 0 to $80 \mu \mathrm{M} / \mathrm{L}$ sodium nitrites.

\section{Evaluation of the Apoptotic Effect of rFgCatB Protein}

Flow cytometry analysis (BD Biosciences, San Jose, California, USA) was carried out to evaluate the apoptosis in PBMCs using the Annexin V-FITC kit (Beyotime, Haimen, Jiangsu, China). PBMCs seeded into a 24-well tissue culture plate at $5 \times 10^{4}$ cells/well in $1 \mathrm{ml}$ RPMI 1640 medium were incubated with the above mentioned concentrations of $\mathrm{rFgCatB}$ protein or equal volume of PBS (control) at $37^{\circ} \mathrm{C}$ with $5 \% \mathrm{CO}_{2}$ for $24 \mathrm{~h}$. Then, cells were washed twice with PBS, re-suspended in binding buffer, and stained with Annexin V and Propidium Iodide (PI) according to the manufacturer's instructions. The results were analyzed using FlowJo 10.

\section{Statistical Analysis}

The statistical analyses were performed by one-way ANOVA, followed by a Dunnett's test or $t$-test using GraphPad Premier 6.0 software package (GraphPad Prism, San Diego, California, USA). Significant differences between rFgCatB-treated and control groups are indicated in the figures by asterisks $(*, P<0.05$; **, $P<0.01$; ***, $P<0.001$ or $\left.{ }^{* * * *}, P<0.0001\right)$. Data were presented as means \pm standard deviation (SD). All experiments were repeated at least three separate times.

\section{RESULTS}

\section{Identification, Cloning, and Expression of rFgCatB Protein}

We performed multiple searches to identify homologous of F. gigantica cathepsin B sequence in the genome of F. hepatica. This analysis identified $F$. hepatica cathepsin B-like protease (GenBank accession no. Z22768.1) sequence, which was used to design $5^{\prime}$ and $3^{\prime}$ primers to amplify the $\mathrm{FgCatB}$ gene. The cDNA fragment of $\mathrm{FgCatB}$ was successfully cloned into the pMD19-T cloning vector and the positive pMD19-T$\mathrm{FgCatB}$ clones were subjected to nucleic acid sequencing. The obtained FgCatB sequence has been submitted to GenBank under accession number MN038412. The amino acid sequence similarity search showed that cathepsin B endopeptidase of F. hepatica (THD22097.1) has the highest similarity $(100 \%$ homology) to $F g C a t B$. The ORF contained 1,038 base-pair (bp) and encoded 345 amino acids. The deduced amino acid sequence predicts the existence of a signal peptide, two $N$-linked glycosylation sites and four protein kinase $\mathrm{C}$ phosphorylation sites, however, no TMH was detected.

\section{SDS-PAGE and Western Blotting Analysis}

To verify the presence of FgCatB protein in F. giganticaderived material, $\mathrm{FgCatB}$ gene fragment was cloned into the pPIC9K vector and the positive clones, designated as $\mathrm{PPIC} 9 \mathrm{~K}-$ $\mathrm{FgCatB}$, were transformed into $P$. pastoris. The recombinant protein ( $\mathrm{rFgCatB})$ was successfully isolated from the culture supernatant of $P$. pastoris. The expected molecular mass of $\mathrm{rFgCatB}$ is $38.2 \mathrm{kDa}$, however after $72 \mathrm{~h}$ of induction with $1 \%$ methanol the purified protein exhibited a heterogeneous molecular mass ranging from $\sim 36-70 \mathrm{kDa}$ on SDS-PAGE. Two bands of approximately 38 and $36 \mathrm{kDa}$ appeared after deglycosylation using endoglycosidase $\mathrm{H}$ (Endo $\mathrm{H}$ ) treatment, which cleaves high-mannose $N$-linked glycans (Figure 1A). Western blot analysis using serum from F. gigantica-infected goats confirmed the specificity of the two bands, which were absent when the Western blot was probed with serum from healthy goats (Figure 1B). 


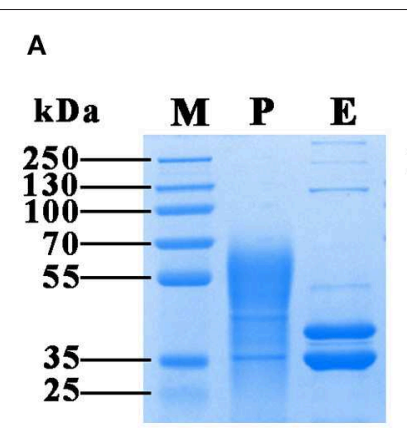

B

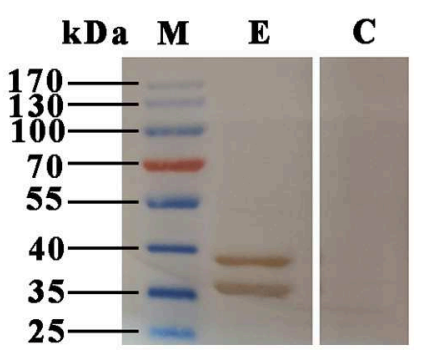

FIGURE 1 | SDS-PAGE and Western blotting analysis of the rFgCatB protein purified from the culture supernatant of $P$. pastoris. (A) Proteins were resolved on $12 \%$ acrylamide gels and stained with Coomassie brilliant blue R250. Lane M, protein molecular weight marker; Lane P, purified rFgCatB appeared heterogeneous and ranged in size from $\sim 36$ to $70 \mathrm{kDa}$; Lane E, rFgCatB treatment with endoglycosidase $\mathrm{H}($ Endo $\mathrm{H})$ revealed two distinct bands at $\sim 38$ and $36 \mathrm{kDa}$. (B) The protein treatment with Endo $\mathrm{H}$ was run under non-reducing conditions, and visualized by immunodetection using specific antibodies and enhanced chemiluminescence. Lane M, protein molecular weight marker; Lane E, was loaded with rFgCatB digested with Endo H. Serum from F. gigantica-infected goats detected $\sim 38$ and 36 kDa bands; Lane C, was loaded with rFgCatB, which did not react with serum of healthy goats.

\section{Enzymatic Activity of rFgCatB}

The activity of cathepsin B was examined using the Fluorometric ab65300 assay kit. Fasciola gigantica-derived rFgCatB enzymatic activity was determined by measuring its ability to cleave the fluorescent synthetic substrate RR-AFC to release free AFC. The results showed that the enzyme activity of $\mathrm{FFCatB}$ is several fold higher than that of the control, confirming the functional activity for cathepsin B (Figure 2).

\section{Binding Affinity of rFgCatB Protein to Goat PBMCs}

Indirect immunofluorescence staining was used to determine the binding affinity of $\mathrm{rFgCatB}$ protein to the surface of PBMCs. By incubating $\mathrm{rFgCatB}$-treated $\mathrm{PBMCs}$ with rabbit anti-rFgCatB antibodies, the localization of the red $\mathrm{Cy} 3$ conjugated goat antirabbit IgG secondary antibody on the cell surface was observed, suggesting successful binding of $\mathrm{rFgCatB}$ to the surface of PBMCs (Figure 3). There was no fluorescence observed in the untreated control cells.

\section{rFgCatB Protein Increased Cytokine Production}

To understand how $\mathrm{rFgCatB}$ modulates cytokine production of PBMCs, the levels of six cytokines, IL-2, IL-4, IL-10, IL-17, IFN- $\gamma$, and TGF- $\beta$, were determined. As shown in Figure 4, when PBMCs were treated with serial concentrations of $\mathrm{rFgCatB}$ protein, the production of all six cytokines was significantly increased compared with control (PBS-treated) PBMCs.

\section{Cytotoxic Effect of rFgCatB Protein}

We examined whether $\mathrm{rFgCatB}$ protein affects the viability of PBMCs. The CCK-8 assay showed that the viability of PBMCs

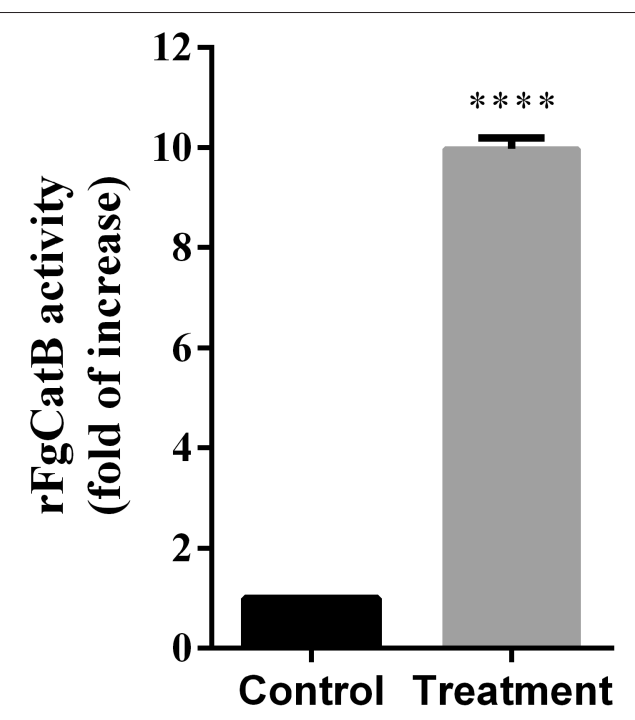

FIGURE 2 | Fasciola gigantica-derived rFgCatB enzymatic activity was determined by examining its ability to cleave the fluorescent synthetic substrate RR-AFC to release free AFC. The enzyme activity of rFgCatB was measured by Cathepsin B Activity Assay Kit as described in the materials and methods and the result showed a high activity of the rFgCatB ( $t$-test, $t=72.68$, $P<0.0001)$. Asterisks indicate statistical significance between rFgCatB sample and cathepsin B inhibitor-treated control sample ( $\left.{ }^{\star \star \star \star} P<0.0001\right)$.

was remarkably decreased following treatment with $\mathrm{rFgCatB}$ protein, at all tested protein concentrations (Figure 5).

\section{Nitric Oxide (NO) Production}

As shown in Figure 6, compared to the control (PBS-treated PBMCs), NO release was slightly increased in $\mathrm{rFgCatB}$-treated PBMCs at $40 \mu \mathrm{g} / \mathrm{ml}$ and was significantly increased in rFgCatBtreated PBMCs at $80 \mu \mathrm{g} / \mathrm{ml}$, but not at 10 or $20 \mu \mathrm{g} / \mathrm{ml}$.

\section{rFgCatB Protein Induced Cell Apoptosis}

To explore whether $\mathrm{rFgCatB}$ protein induces apoptosis in goat PBMCs, Annexin V-FITC apoptosis assay was used. The $\mathrm{rFgCatB}$ protein significantly induced apoptosis in PBMCs at all tested concentrations compared to PBS-treated, control PBMCs (Figure 7). The apoptosis was induced in a dosedependent manner with the percentage of apoptotic cells treated with $\mathrm{rFgCatB}$ at $10,20,40$, and $80 \mu \mathrm{g} / \mathrm{ml}$ were 28.88 $\pm 2.631 \%, 30.95 \pm 3.128 \%, 33.50 \pm 2.152 \%$, and $46.17 \pm$ $5.955 \%$, respectively.

\section{DISCUSSION}

In this study, we cloned and expressed the gene encoding cathepsin B of $F$. gigantica in the methylotrophic yeast $P$. pastoris. Although the expected size of the purified $\mathrm{rFgCatB}$ protein with six-histidine tag is $38.2 \mathrm{kDa}$, a significant increase in its molecular weight was observed. Yeast expression system has been known to introduce post-translational modifications such as glycosylation which may affect protein folding. Also, recombinant proteins produced in $P$. pastoris tend to be 


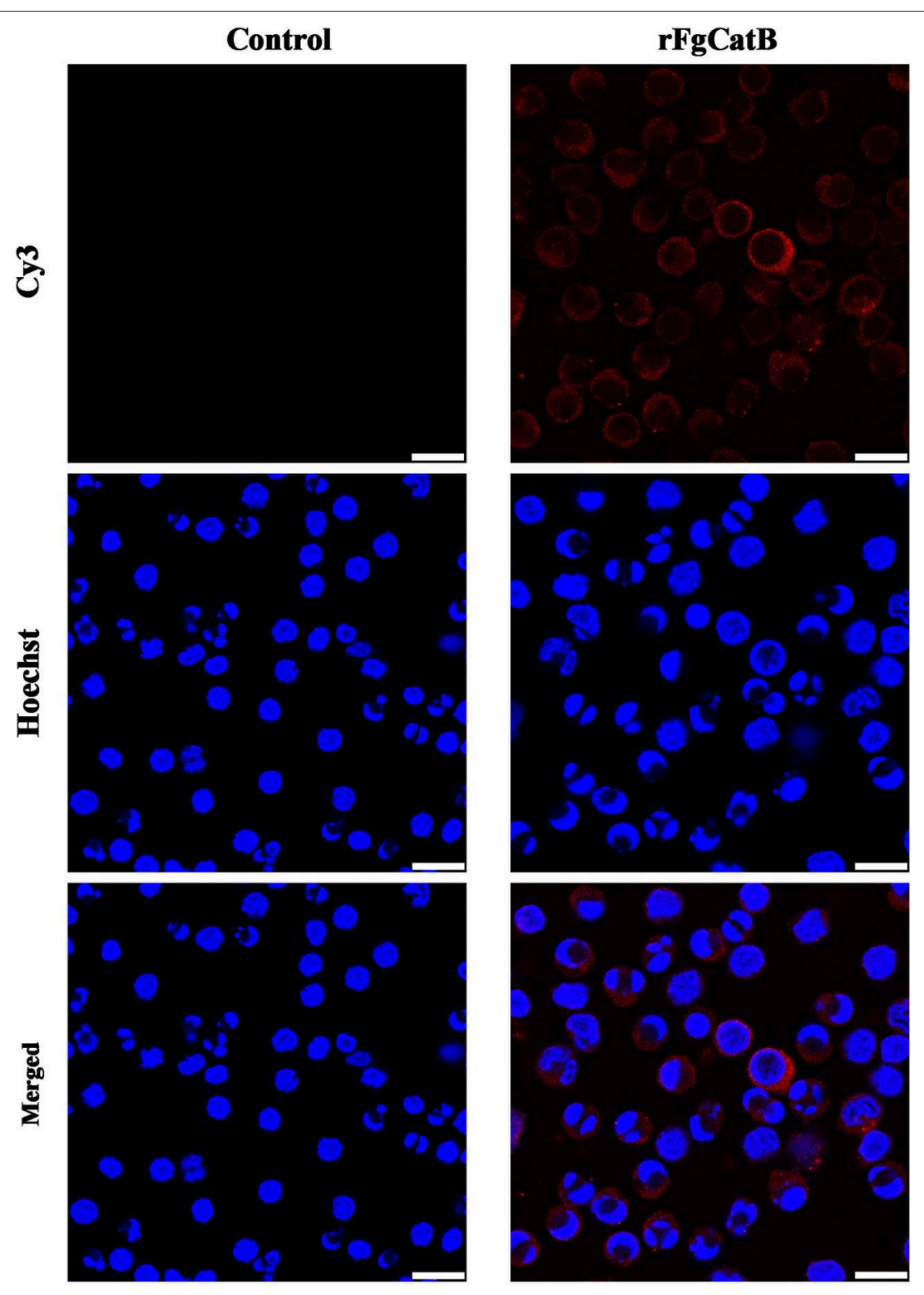

FIGURE 3 | Localization of Fasciola gigantica-derived rFgCatB protein on the surface of PBMCs. Cells were treated with rFgCatB and incubated with rabbit anti-rFgCatB primary antibody. Hoechst (blue) and Cy3-conjugated secondary antibody (red) were used to stain host cell nuclei and rFgCatB protein, respectively. Surface localization was observed in rFgCatB-treated cells, whereas no staining was detected in untreated (control) cells. Scale bars, $10 \mu \mathrm{m}$.

hypermannosylated. On SDS-PAGE gels, rFgCatB appeared as a group of bands with molecular weights between $\sim 36$ and $70 \mathrm{kDa}$. The observed heterogeneity in the size of the protein may be attributed to $N$-linked glycosylation (19). Deglycosylation of $\mathrm{rFgCatB}$ using Endo $\mathrm{H}$ revealed $\sim 38 \mathrm{kDa}$ band, which corresponds to the theoretical molecular mass of $\mathrm{rFgCatB}$, and another band with molecular masse of $36 \mathrm{kDa}$, suggesting the presence of two different glycosylated species (i.e., diglycosylated forms) of $\mathrm{rFgCatB}$, particularly, as both reacted in Western blot. This type of finding has been also reported for cathepsin B from the Asiatic liver fluke Opisthorchis viverrini (20).
Our results showed that $\mathrm{rFgCatB}$ induced expression of Th1 type cytokines (IL-2 and IFN- $\gamma$ ), Th2 type cytokines (IL-4, IL-10, and TGF- $\beta$ ), and Th17 type cytokine (IL-17), suggesting that $\mathrm{rFgCatB}$ can induce a mixed $\mathrm{T}$ helper 1 (Th1)-, Th2-, and Th17-type immune response. The high levels of pro-inflammatory cytokines (IL-2 and IFN- $\gamma$ ) and activation of monocytes have been associated with intestinal pathology and release of $\mathrm{NO}$ to limit the fluke growth (21-23). On the other hand, high expression of Th2 anti-inflammatory cytokines can facilitate parasite persistence, while minimizing host tissue damage (24-27). For example, the anti-inflammatory cytokine IL-4 inhibits 

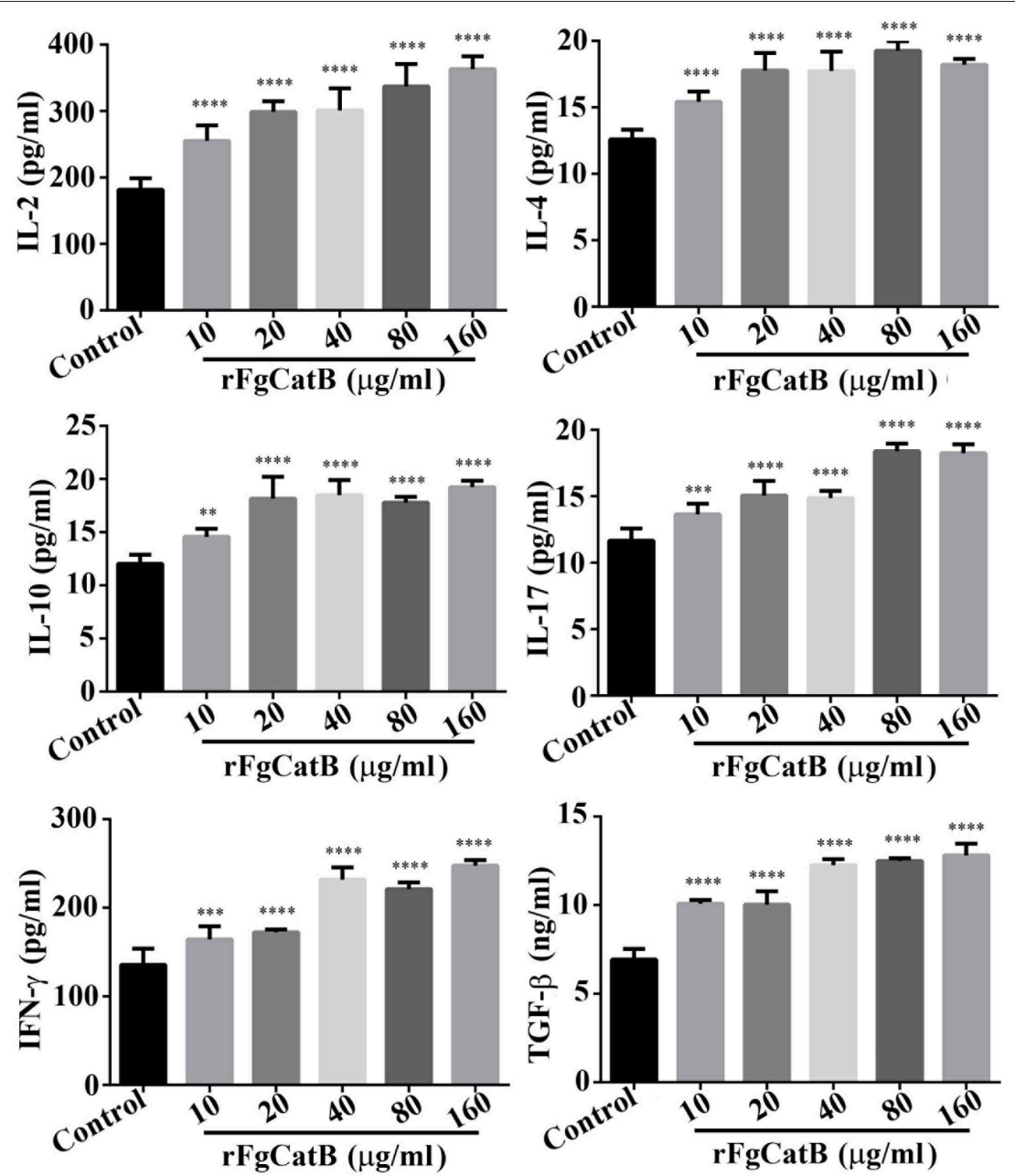

FIGURE 4 | rFgCatB protein stimulated the production of cytokines. Goat PBMCs were incubated for $72 \mathrm{~h}$ in the presence of PBS or serial concentrations of $\mathrm{rFgCatB}$ protein. The levels of cytokines in the supernatant of cultured PBMCs were quantified by ELISA. Results showed that rFgCatB induced the expression of all examined cytokines in a dose-dependent manner. Graphs represent means \pm standard deviations of data from three independent biological replicates (IL-2 (10 $\mu \mathrm{g} / \mathrm{ml}$ : $F_{(5,36)}=46.98, P<0.0001 ; 20 \mu \mathrm{g} / \mathrm{ml}: F_{(5,36)}=46.98, P<0.0001 ; 40 \mu \mathrm{g} / \mathrm{ml}: F_{(5,36)}=46.98, P<0.0001 ; 80 \mu \mathrm{g} / \mathrm{ml}: F_{(5,36)}=46.98, P<0.0001 ; 160 \mu \mathrm{g} / \mathrm{ml}:$ $\left.F_{(5,36)}=46.98, P<0.0001\right), \mathrm{IL}-4\left(10 \mu \mathrm{g} / \mathrm{ml}: F_{(5,36)}=43.65, P<0.0001 ; 20 \mu \mathrm{g} / \mathrm{ml}: F_{(5,36)}=43.65, P<0.0001 ; 40 \mu \mathrm{g} / \mathrm{ml}: F_{(5,36)}=43.65, P<0.0001 ; 80\right.$ $\left.\mu \mathrm{g} / \mathrm{ml}: F_{(5,36)}=43.65, P<0.0001 ; 160 \mu \mathrm{g} / \mathrm{ml}: F_{(5,36)}=43.65, P<0.0001\right), \mathrm{IL}-10\left(10 \mu \mathrm{g} / \mathrm{ml}: F_{(5,36)}=40.51, P=0.0012 ; 20 \mu \mathrm{g} / \mathrm{ml}: F_{(5,36)}=40.51\right.$, $\left.P<0.0001 ; 40 \mu \mathrm{g} / \mathrm{ml}: F_{(5,36)}=40.51, P<0.0001 ; 80 \mu \mathrm{g} / \mathrm{ml}: F_{(5,36)}=40.51, P<0.0001 ; 160 \mu \mathrm{g} / \mathrm{ml}: F_{(5,36)}=40.51, P<0.0001\right), \mathrm{IL}-17(10 \mu \mathrm{g} / \mathrm{ml}:$ $F_{(5,36)}=77.39, P=0.0002 ; 20 \mu \mathrm{g} / \mathrm{ml}: F_{(5,36)}=77.39, P<0.0001 ; 40 \mu \mathrm{g} / \mathrm{ml}: F_{(5,36)}=77.39, P<0.0001 ; 80 \mu \mathrm{g} / \mathrm{ml}: F_{(5,36)}=77.39, P<0.0001 ; 160 \mu \mathrm{g} / \mathrm{ml}:$ $\left.F_{(5,36)}=77.39, P<0.0001\right)$, TGF- $\beta\left(10 \mu \mathrm{g} / \mathrm{ml}: F_{(5,36)}=137.5, P<0.0001 ; 20 \mu \mathrm{g} / \mathrm{ml}: F_{(5,36)}=137.5, P<0.0001 ; 40 \mu \mathrm{g} / \mathrm{ml}: F_{(5,36)}=137.5, P<0.0001 ; 80\right.$ $\left.\mu \mathrm{g} / \mathrm{ml}: F_{(5,36)}=137.5, P<0.0001 ; 160 \mu \mathrm{g} / \mathrm{ml}: F_{(5,36)}=137.5, P<0.0001\right)$, and IFN- $\gamma\left(10 \mu \mathrm{g} / \mathrm{ml}: F_{(5,36)}=96.82, P=0.0003 ; 20 \mu \mathrm{g} / \mathrm{ml}: F_{(5,36)}=96.82\right.$, $\left.P<0.0001 ; 40 \mu \mathrm{g} / \mathrm{ml}: F_{(5,36)}=96.82, P<0.0001 ; 80 \mu \mathrm{g} / \mathrm{ml}: F_{(5,36)}=96.82, P<0.0001 ; 160 \mu \mathrm{g} / \mathrm{ml}: F_{(5,36)}=96.82, P<0.0001\right)$. Asterisks indicate statistical significance between treated and untreated control PBMCs $\left({ }^{\star \star} P<0.01\right.$; ${ }^{* \star \star} P<0.001 ;{ }^{\star * \star *} P<0.0001$ compared with control).

NO production (28) and promotes Th2 differentiation (29), thereby facilitating the production of other antiinflammatory cytokines (e.g., IL-10 and TGF- $\beta$ ) and inhibiting pro-inflammatory cytokines (e.g., IL-2 and IFN$\gamma)(30,31)$. Also, IL-10 decreases the production of IFN- $\gamma$ and IL-2 $(22,31)$.

TGF- $\beta$, together with other inflammatory cytokines, can promote Th17 differentiation (32-34). Th17 cells play an important role in host protection against various parasitic infections by recruiting macrophages and neutrophils to infected tissues, and through the modulation of Th1/Th2 balance (34-36).
The role of IL-17 in the inflammatory process during $F$. gigantica infection has been reported $(37,38)$. Interestingly, TGF- $\beta$ can inhibit $\mathrm{T}$ cell proliferation by suppressing the production of IL-2, and inhibiting the differentiation of Th1 and Th2 cells (39).

We have previously shown that F. gigantica proteins, rFg14-334 and rFgRab10, inhibit cell proliferation, and induce apoptosis and NO production in goat PBMCs $(6,7)$. The results of the present study lend further support to these previous findings, where rFgCatB was found to bind to the surface of PBMCs similar to what we have demonstrated for rFg14-34 and rFgRab10 proteins $(6,7)$, and to reduce the viability 
and increase apoptosis of PBMCs. The biological relevance of the pro-apoptotic effect of $\mathrm{rFgCatB}$ on PBMCs remains to be determined. However, induction of apoptosis, rather than necrosis, may favor the parasite's persistence because apoptotic cell death does not provoke inflammatory response (40), which can be detrimental to the parasite's survival inside the host.

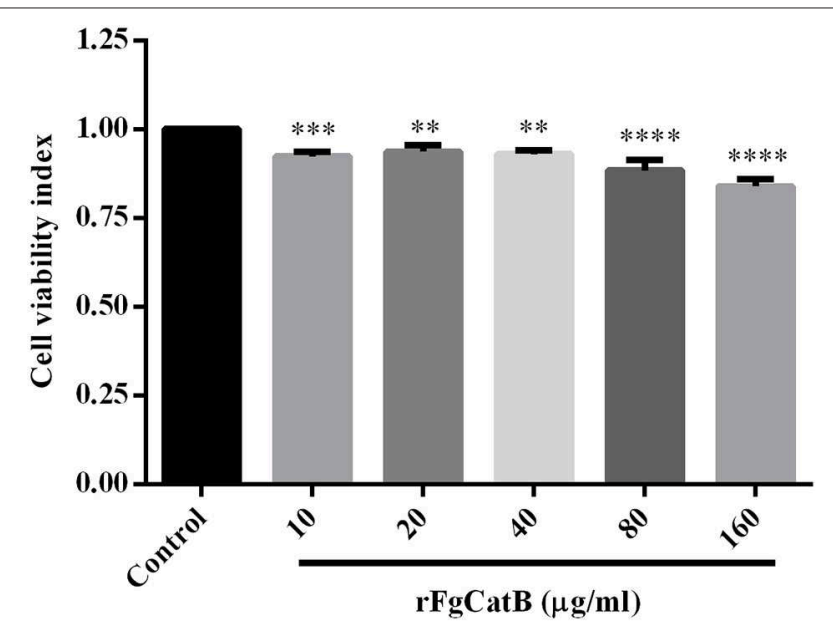

FIGURE 5 | Effect of $r F g C a t B$ protein on PBMC viability. Goat PBMCs were treated with PBS or with serial concentrations of $\mathrm{rFgCatB}$ protein and incubated for $48 \mathrm{~h}$ at $37^{\circ} \mathrm{C}$ at $5 \% \mathrm{CO}_{2}$. Viability of cells was determined using CCK-8 assay. Results indicate that $r F g C a t B$ protein significantly reduced the viability of PBMCs in a dose-dependent manner. Graphs represent means \pm standard deviations of data from three independent biological replicates (10 $\mu \mathrm{g} / \mathrm{ml}$ : ANOVA, $F_{(5,12)}=28.50, P=0.0007 ; 20 \mu \mathrm{g} / \mathrm{ml}$ : ANOVA,

$F_{(5,12)}=28.50, P=0.0035 ; 40 \mu \mathrm{g} / \mathrm{ml}$ : ANOVA, $F_{(5,12)}=28.50, P=0.0015$; $80 \mu \mathrm{g} / \mathrm{ml}$ : ANOVA, $F_{(5,12)}=28.50, P<0.0001 ; 160 \mu \mathrm{g} / \mathrm{ml}$ : ANOVA,

$\left.F_{(5,12)}=28.50, P<0.0001\right)$. Asterisks indicate significant differences between rFgCatB-treated and PBS-treated control cells ( ${ }^{\star \star} P<0.01$; ${ }^{\star * \star} P<0.001 ;{ }^{\star \star \star \star} P<0.0001$ compared with control).
The antiproliferative and pro-apoptotic effects of $\mathrm{E} / \mathrm{S}$ products of Fasciola spp. on immune cells are some of the strategies used by these liver flukes to hamper immune defenses, leaving the host more vulnerable to infection. F. hepatica-derived E/S products have been shown to inhibit the proliferation of sheep lymphoid cells, especially $\mathrm{CD} 4^{+} \mathrm{T}$ lymphocytes (41-43), reduce the proliferation of rat spleen mononuclear cells (44) and induce apoptosis of murine

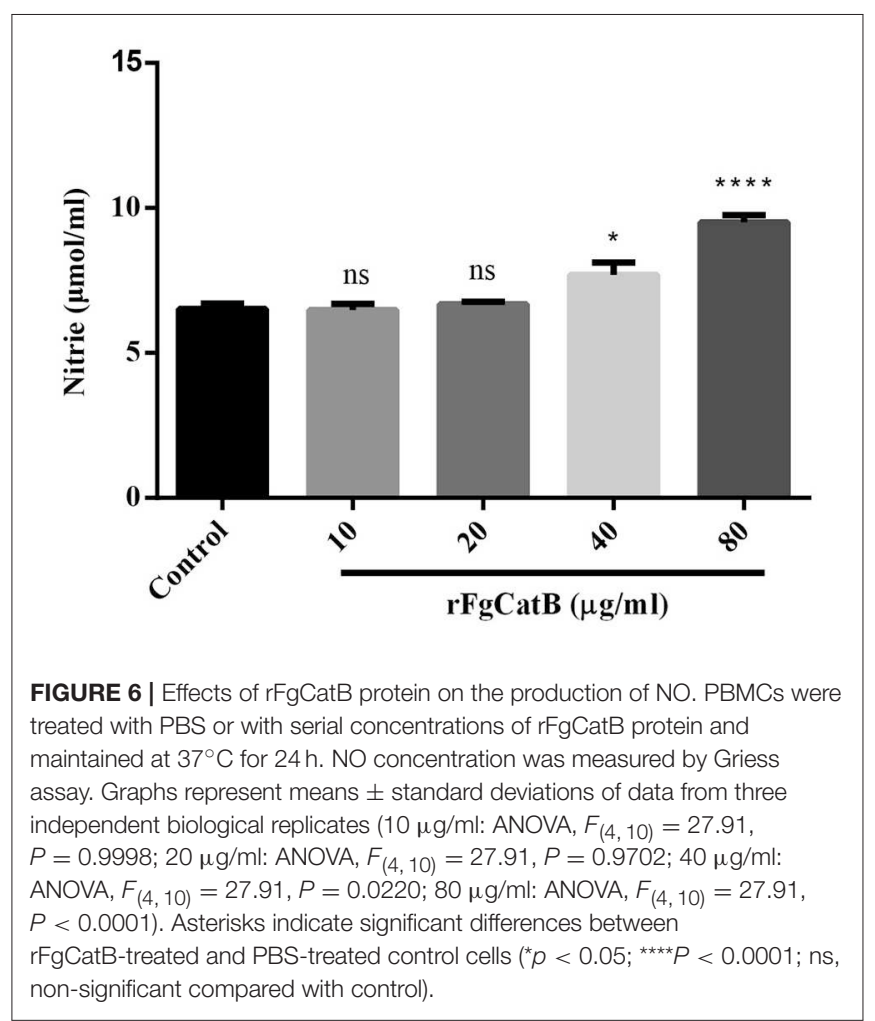

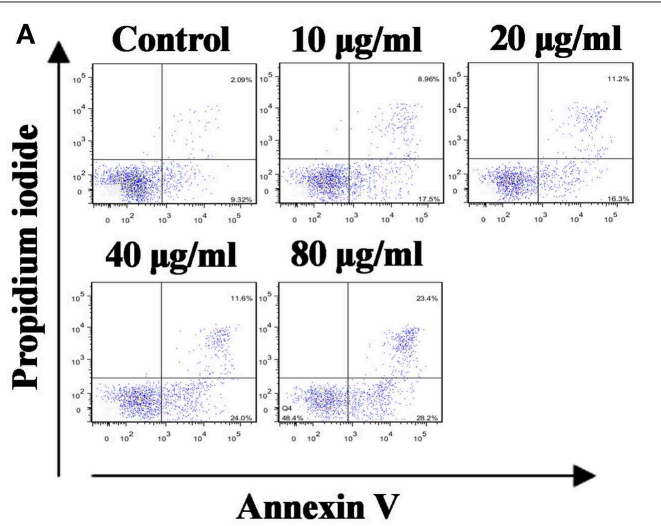

B

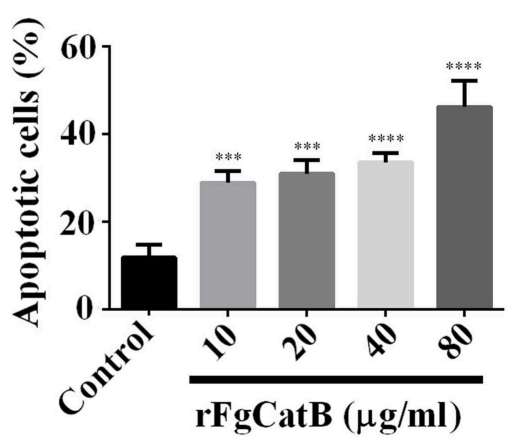

FIGURE 7 | rFgCatB protein induced apoptosis in goat PBMCs. Annexin V/PI staining was used to quantify apoptotic cells by flow cytometry. (A) The FACS plot showing apoptosis of PBMCs in response to exposure to rFgCatB protein. (B) Apoptotic cells (Annexin V+/PI-) were plotted and compared with the percentage of cell population. Graphs represent means \pm standard deviations of data from three independent biological replicates $\left(10 \mu \mathrm{g} / \mathrm{ml}: \mathrm{ANOVA}, F_{(4,10)}=34.92, P=0.0006 ; 20\right.$ $\mu \mathrm{g} / \mathrm{ml}$ : ANOVA, $F_{(4,10)}=34.92, P=0.0003 ; 40 \mu \mathrm{g} / \mathrm{ml}$ : ANOVA, $F(4,10)=34.92, P<0.0001 ; 80 \mu \mathrm{g} / \mathrm{ml}$ : ANOVA, $\left.F_{(4,10)}=34.92, P<0.0001\right)$. The asterisks indicate significant differences between rFgCatB-treated and PBS-treated control goat PBMCs $\left({ }^{\star \star \star} P<0.001\right.$; ${ }^{\star \star \star \star} P<0.0001$ compared with control). 
eosinophils and peritoneal macrophages (45, 46). Also, immunosuppression of $\mathrm{CD} 4^{+} \mathrm{T}$ lymphocytes has been observed in F. hepatica-infected goats (47). Additionally, F. hepatica can induce apoptosis in sheep PBMCs by up-regulating the expression of TNF- $\alpha$ and TNFR1/TNFR2 (48). The induction of apoptosis in sheep eosinophils (49) and peritoneal leucocytes (50) has been suggested to play a role in the pathogenesis of $F$. hepatica by supporting the survival of the juvenile parasites during the migratory and biliary stages of infection.

In summary, our data show that $\mathrm{rFgCatB}$ interacts with serum from goats infected with $F$. gigantica and accumulates at the surface of PBMCs. The importance of our data resides in the fact that $\mathrm{rFgCatB}$ represents a new mechanism for F. gigantica to evade the host's immune response through modulation of the immune response and biological functions of PBMCs. Exposure of these cells to $\mathrm{rFgCatB}$ caused increased production of cytokines (IL-2, IL-4, IL-10, IL-17, TGF- $\beta$, and IFN- $\gamma$ ), increased NO production, increased apoptosis, and inhibition of cell viability. Our data provide a proof of concept that $\mathrm{rFgCatB}$ is involved $F$. gigantica-interaction with immune cells. In the light of these findings and given that $\mathrm{rFgCatB}$ and other $F$. giganticaderived proteins (e.g., rFg14-3-34 and rFgRab10) can modulate key cellular and immunological functions of goat PBMCs, future work should focus on identifying the appropriate synergistic combinations of these proteins to develop a cocktail vaccine for testing against $F$. gigantica infection.

\section{DATA AVAILABILITY}

All datasets generated for this study are included in the manuscript.

\section{REFERENCES}

1. Mas-Coma S. Epidemiology of fascioliasis in human endemic areas. $J$ Helminthol. (2005) 79:207-16. doi: 10.1079/JOH2005296

2. Mungube EO, Bauni SM, Tenhagen BA, Wamae LW, Nginyi JM, Mugambi JM. The prevalence and economic significance of Fasciola gigantica and Stilesia hepatica in slaughtered animals in the semi-arid coastal Kenya. Trop Anim Health Prod. (2006) 38:475-83. doi: 10.1007/s11250-006-4394-4

3. Shokiera KM, Aboelhadid SM, Waleed MA. Efficacy of five anthelmintics against a natural Fasciola species infection in cattle. Beni Suef Univ J Basic Appl Sci. (2013) 2:41-5. doi: 10.1016/j.bjbas.2013.09.006

4. Berasain P, Carmona C, Frangione B, Dalton JP, Goni F. Fasciola hepatica: parasite-secreted proteinases degrade all human IgG subclasses: determination of the specific cleavage sites and identification of the immunoglobulin fragments produced. Exp Parasitol. (2000) 94:99-110. doi: 10.1006/expr.1999.4479

5. Dalton JP, Neill SO, Stack C, Collins P, Walshe A, Sekiya M, et al. Fasciola hepatica cathepsin L-like proteases: biology, function, and potential in the development of first generation liver fluke vaccines. Inter J Parasitol. (2003) 33:1173-81. doi: 10.1016/S0020-7519(03)00171-1

6. Tian AL, Lu M, Calderon-Mantilla G, Petsalaki E, Dottorini T, Tian X, et al. A recombinant Fasciola gigantica 14-3-3 epsilon protein (rFg14-3-3e) modulates various functions of goat peripheral blood mononuclear cells. Parasit Vectors. (2018) 11:152. doi: 10.1186/s13071-018-2745-4

7. Tian AL, Lu M, Zhang FK, Calderon-Mantilla G, Petsalaki E, Tian X, et al. The pervasive effects of recombinant Fasciola gigantica Ras-related protein Rab10 on the functions of goat peripheral blood mononuclear cells. Parasit Vectors. (2018) 11:579. doi: 10.1186/s13071-018-3148-2

\section{ETHICS STATEMENT}

All experimental protocols were reviewed and approved by the Animal Administration and Ethics Committee of Lanzhou Veterinary Research Institute, Chinese Academy of Agricultural Sciences (Permit No. 2018-012). All animal experiments were performed in strict compliance with the Animal Ethics Procedures and Guidelines of the People's Republic of China. All efforts were made to minimize the suffering of animals, and daily health checks were performed during the entire experiments.

\section{AUTHOR CONTRIBUTIONS}

$\mathrm{X}-\mathrm{QZ}, \mathrm{XL}$, and HE conceived the idea, planned the experiments, and provided critical feedback. DC performed the experiments, analyzed the data, and drafted the manuscript with the help of HE. A-LT, J-LH, J-XL, XT, and X-DY participated in the implementation of the study. All authors read and approved the final manuscript.

\section{FUNDING}

This work was supported by the National Key Basic Research Program (973 Program) of China (Grant No. 2015CB150300) and the Agricultural Science and Technology Innovation Program (ASTIP) (Grant No. CAAS-ASTIP-2016-LVRI-03).

\section{ACKNOWLEDGMENTS}

We thank Professor Kevin Gough (University of Nottingham) and Professor David Buttle (University of Sheffield) for helpful comments and constructive suggestions.

8. Beckham SA, Piedrafita D, Phillips CI, Samarawickrema N, Law RH, Smooker PM, et al. A major cathepsin B protease from the liver fluke Fasciola hepatica has atypical active site features and a potential role in the digestive tract of newly excysted juvenile parasites. Int J Biochem Cell Biol. (2009) 41:1601-12. doi: 10.1016/j.biocel.2009.02.003

9. Smooker PM, Jayaraj R, Pike RN, Spithill TW. Cathepsin B proteases of flukes: the key to facilitating parasite control? Trends Parasitol. (2010) 26:506-14. doi: 10.1016/j.pt.2010.06.001

10. Norbury LJ, Beckham S, Pike RN, Grams R, Spithill TW, Fecondo JV, et al. Adult and juvenile Fasciola cathepsin L proteases: different enzymes for different roles. Biochimie. (2011) 93:604-11. doi: 10.1016/j.biochi.2010.12.004

11. McKerrow JH, Caffrey C, Kelly B, Loke P, Sajid M. Proteases in parasitic diseases. Annu Rev Pathol. (2006) 1:497-536. doi: 10.1146/annurev.pathol.1.110304.100151

12. Robinson MW, Menon R, Donnelly SM, Dalton JP, Ranganathan S. An integrated transcriptomics and proteomics analysis of the secretome of the helminth pathogen Fasciola hepatica: proteins associated with invasion and infection of the mammalian host. Mol Cell Proteomics. (2009) 8:1891-907. doi: 10.1074/mcp.M900045-MCP200

13. Dalton JP, Robinson MW, Mulcahy G, O’Neill SM, Donnelly S. Immunomodulatory molecules of Fasciola hepatica: candidates for both vaccine and immunotherapeutic development. Vet Parasitol. (2013) 195:272-85. doi: 10.1016/j.vetpar.2013. 04.008

14. Sethadavit M, Meemon K, Jardim A, Spithill TW, Sobhon P. Identification, expression and immunolocalization of cathepsin B3, a stage-specific antigen expressed by juvenile Fasciola gigantica. Acta Trop. (2009) 112:164-73. doi: 10.1016/j.actatropica.2009.07.016 
15. Chantree $\mathrm{P}$, Wanichanon $\mathrm{C}$, Phatsara M, Meemon K, Sobhon P. Characterization and expression of cathepsin B2 in Fasciola gigantica. Exp Parasitol. (2012) 132:249-56. doi: 10.1016/j.exppara.2012.07.011

16. Chantree $\mathrm{P}$, Phatsara $\mathrm{M}$, Meemon K, Chaichanasak P, Changklungmoa $\mathrm{N}$, Kueakhai $\mathrm{P}$, et al. Vaccine potential of recombinant cathepsin B against Fasciola gigantica. Exp Parasitol. (2013) 135:102-9. doi: 10.1016/j.exppara.2013.06.010

17. Siricoon S, Vichasri Grams S, Lertwongvisarn K, Abdullohfakeeyah M, Smooker PM, Grams R. Fasciola gigantica cathepsin B5 is an acidic endoand exopeptidase of the immature and mature parasite. Biochimie. (2015) 119:6-15. doi: 10.1016/j.biochi.2015.10.005

18. Huang WY, He B, Wang CR, Zhu XQ. Characterisation of Fasciola species from Mainland China by ITS-2 ribosomal DNA sequence. Vet Parasitol. (2004) 120:75-83. doi: 10.1016/j.vetpar.2003.12.006

19. Trimble RB, Maley F. Optimizing hydrolysis of N-linked high-mannose oligosaccharides by endo-beta-N-acetylglucosaminidase H. Anal Biochem. (1984) 141:515-22. doi: 10.1016/0003-2697(84)90080-0

20. Sripa J, Laha T, To J, Brindley PJ, Sripa B, Kaewkes S, et al. Secreted cysteine proteases of the carcinogenic liver fluke, Opisthorchis viverrini: regulation of cathepsin F activation by autocatalysis and trans-processing by cathepsin B. Cell Microbiol. (2010) 12:781-95. doi: 10.1111/j.1462-5822.2010.01433.x

21. Alonso-Trujillo J, Rivera-Montoya I, Rodriguez-Sosa M, Terrazas LI. Nitric oxide contributes to host resistance against experimental Taenia crassiceps cysticercosis. Parasitol Res. (2007) 100:1341-50. doi: 10.1007/s00436-006-0424-4

22. Moura VB, Lima SB, Matos-Silva H, Vinaud MC, Loyola PR, Lino RS. Cellular immune response in intraventricular experimental neurocysticercosis.

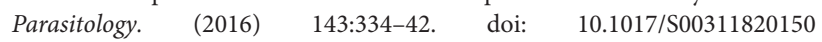
01572

23. Munoz-Carrillo JL, Contreras-Cordero JF, Munoz-Lopez JL, MaldonadoTapia CH, Munoz-Escobedo JJ, Moreno-Garcia MA. Resiniferatoxin modulates the Th1 immune response and protects the host during intestinal nematode infection. Parasite Immunol. (2017) 39:e12448. doi: 10.1111/pim. 12448

24. Maizels RM, Yazdanbakhsh M. Immune regulation by helminth parasites: cellular and molecular mechanisms. Nat Rev Immunol. (2003) 3:733-44. doi: $10.1038 /$ nri1183

25. McKee AS, Pearce EJ. CD25+CD4+ Cells contribute to Th2 polarization during helminth infection by suppressing Th1 response development. J Immunol. (2004) 173:1224-31. doi: 10.4049/jimmunol.173. 2.1224

26. Falcon C, Carranza F, Martinez FF, Knubel CP, Masih DT, Motran CC, et al. Excretory-secretory products (ESP) from Fasciola hepatica induce tolerogenic properties in myeloid dendritic cells. Vet Immunol Immunopathol. (2010) 137:36-46. doi: 10.1016/j.vetimm.2010.04.007

27. Ma X, Wang L, Zhao H, Pang N, Zhang F, Jiang T, et al. Th17 cells are associated with the Th1/Th2cell balance during Echinococcus multilocularis infection. Mol Med Rep. (2014) 10:236-40. doi: 10.3892/mmr.2014.2170

28. Rutschman R, Lang R, Hesse M, Ihle JN, Wynn TA, Murray PJ. Cutting edge: Stat6-dependent substrate depletion regulates nitric oxide production. J Immunol. (2001) 166:2173-7. doi: 10.4049/jimmunol.166. 4.2173

29. Paul WE. Interleukin 4: signalling mechanisms and control of $\mathrm{T}$ cell differentiation. Ciba Found Symp. (1997) 204:208-16; discussion 216-09. doi: 10.1002/9780470515280.ch14

30. Steinke JW, Borish L. Th2 cytokines and asthma. Interleukin-4: its role in the pathogenesis of asthma, and targeting it for asthma treatment with interleukin-4 receptor antagonists. Respir Res. (2001) 2:66-70. doi: 10.1186/rr40

31. Vazquez MI, Catalan-Dibene J, Zlotnik A. B cells responses and cytokine production are regulated by their immune microenvironment. Cytokine. (2015) 74:318-26. doi: 10.1016/j.cyto.2015.02.007

32. Veldhoen M, Hocking RJ, Atkins CJ, Locksley RM, Stockinger B. TGFbeta in the context of an inflammatory cytokine milieu supports de novo differentiation of IL-17-producing T cells. Immunity. (2006) 24:179-89. doi: 10.1016/j.immuni.2006.01.001

33. Veldhoen M, Stockinger B. TGFbeta1, a "Jack of all trades": the link with proinflammatory IL-17-producing T cells. Trends Immunol. (2006) 27:358-61. doi: 10.1016/j.it.2006.06.001
34. Tallima H, Salah M, Guirguis FR, El Ridi R. Transforming growth factor-beta and Th17 responses in resistance to primary murine schistosomiasis mansoni. Cytokine. (2009) 48:239-45. doi: 10.1016/j.cyto.2009.07.581

35. Park H, Li Z, Yang XO, Chang SH, Nurieva R, Wang YH, et al. A distinct lineage of CD4 $\mathrm{T}$ cells regulates tissue inflammation by producing interleukin 17. Nat Immunol. (2005) 6:1133-41. doi: 10.1038/ni1261

36. Bi Y, Liu G, Yang R. Th17 cell induction and immune regulatory effects. J Cell Physiol. (2007) 211:273-8. doi: 10.1002/jcp.20973

37. Shi W, Wei ZY, Elsheikha HM, Zhang FK, Sheng ZA, Lu KJ, et al. Dynamic expression of cytokine and transcription factor genes during experimental Fasciola gigantica infection in buffaloes. Parasit Vectors. (2017) 10:602. doi: 10.1186/s13071-017-2538-1

38. Zhang FK, Guo AJ, Hou JL, Sun MM, Sheng ZA, Zhang XX, et al. Serum levels of cytokines in water buffaloes experimentally infected with Fasciola gigantica. Vet Parasitol. (2017) 244:97-101. doi: 10.1016/j.vetpar.2017.07.028

39. Li MO, Wan YY, Sanjabi S, Robertson AK, Flavell RA. Transforming growth factor-beta regulation of immune responses. Annu Rev Immunol. (2006) 24:99-146. doi: 10.1146/annurev.immunol.24.021605.090737

40. Rock KL, Kono H. The inflammatory response to cell death. Annu Rev Pathol. (2008) 3:99-126. doi: 10.1146/annurev.pathmechdis.3.121806.151456

41. Moreau E, Herve S, Yu ZW, Alain C. Modulation of sheep lymphocyte responses by Fasciola hepatica excretory-secretory products. Vet Parasitol. (2002) 108:207-15. doi: 10.1016/S0304-4017(02)00196-6

42. Prowse RK, Chaplin P, Robinson HC, Spithill TW. Fasciola hepatica cathepsin L suppresses sheep lymphocyte proliferation in vitro and modulates surface CD4 expression on human and ovine T cells. Parasite Immunol. (2002) 24:57-66. doi: 10.1046/j.0141-9838.2001.00438.x

43. Zhang W, Moreau E, Peigne F, Huang W, Chauvin A. Comparison of modulation of sheep, mouse and buffalo lymphocyte responses by Fasciola hepatica and Fasciola gigantica excretory-secretory products. Parasitol Res. (2005) 95:333-8. doi: 10.1007/s00436-005-1306-x

44. Cervi L, Masih DT. Inhibition of spleen cell proliferative response to mitogens by excretory-secretory antigens of Fasciola hepatica. Int J Parasitol. (1997) 27:573-9. doi: 10.1016/S0020-7519(96)00188-9

45. Serradell MC, Guasconi L, Cervi L, Chiapello LS, Masih DT. Excretorysecretory products from Fasciola hepatica induce eosinophil apoptosis by a caspase-dependent mechanism. Vet Immunol Immunopathol. (2007) 117:197208. doi: 10.1016/j.vetimm.2007.03.007

46. Guasconi L, Serradell MC, Masih DT. Fasciola hepatica products induce apoptosis of peritoneal macrophages. Vet Immunol Immunopathol. (2012) 148:359-63. doi: 10.1016/j.vetimm.2012.06.022

47. Zafra R, Perez J, Buffoni L, Martinez-Moreno FJ, Acosta I, Mozos E, et al. Peripheral blood lymphocyte subsets in Fasciola hepatica infected and immunised goats. Vet Immunol Immunopathol. (2013) 155:135-8. doi: 10.1016/j.vetimm.2013.06.006

48. Fu Y, Chryssafidis AL, Browne JA, O'Sullivan J, McGettigan PA, Mulcahy G. Transcriptomic study on ovine immune responses to Fasciola hepatica infection. PLoS Negl Trop Dis. (2016) 10:e0005015. doi: 10.1371/journal.pntd.0005015

49. Escamilla A, Bautista MJ, Zafra R, Pacheco IL, Ruiz MT, Martinez-Cruz $\mathrm{S}$, et al. Fasciola hepatica induces eosinophil apoptosis in the migratory and biliary stages of infection in sheep. Vet Parasitol. (2016) 216:84-8. doi: 10.1016/j.vetpar.2015.12.013

50. Escamilla A, Perez-Caballero R, Zafra R, Bautista MJ, Pacheco IL, Ruiz MT, et al. Apoptosis of peritoneal leucocytes during early stages of Fasciola hepatica infections in sheep. Vet Parasitol. (2017) 238:49-53. doi: 10.1016/j.vetpar.2017.03.015

Conflict of Interest Statement: The authors declare that the research was conducted in the absence of any commercial or financial relationships that could be construed as a potential conflict of interest.

Copyright (C) 2019 Chen, Tian, Hou, Li, Tian, Yuan, Li, Elsheikha and Zhu. This is an open-access article distributed under the terms of the Creative Commons Attribution License (CC BY). The use, distribution or reproduction in other forums is permitted, provided the original author(s) and the copyright owner(s) are credited and that the original publication in this journal is cited, in accordance with accepted academic practice. No use, distribution or reproduction is permitted which does not comply with these terms. 